Non-Symmetric Cardinal Value Allocations

Author(s): Allen J. Scafuri and Nicholas C. Yannelis

Source: Econometrica, Vol. 52, No. 6 (Nov., 1984), pp. 1365-1368

Published by: The Econometric Society

Stable URL: http://www.jstor.org/stable/1913510

Accessed: 19/02/2010 12:55

Your use of the JSTOR archive indicates your acceptance of JSTOR's Terms and Conditions of Use, available at http://www.jstor.org/page/info/about/policies/terms.jsp. JSTOR's Terms and Conditions of Use provides, in part, that unless you have obtained prior permission, you may not download an entire issue of a journal or multiple copies of articles, and you may use content in the JSTOR archive only for your personal, non-commercial use.

Please contact the publisher regarding any further use of this work. Publisher contact information may be obtained at http://www.jstor.org/action/showPublisher?publisherCode=econosoc.

Each copy of any part of a JSTOR transmission must contain the same copyright notice that appears on the screen or printed page of such transmission.

JSTOR is a not-for-profit service that helps scholars, researchers, and students discover, use, and build upon a wide range of content in a trusted digital archive. We use information technology and tools to increase productivity and facilitate new forms of scholarship. For more information about JSTOR, please contact support@jstor.org. 


\title{
NON-SYMMETRIC CARDINAL VALUE ALLOCATIONS
}

\author{
By Allen J. Scafuri and Nicholas C. Yannelis ${ }^{1}$
}

\begin{abstract}
It is shown that cardinal value allocations may fail to be symmetric. Specifically, agents with identical preferences and identical endowments can be treated very differently at a cardinal value allocation. This casts further doubt on the interpretation of the weights as "endogenous utility comparisons."
\end{abstract}

\section{INTRODUCTION}

IN A RECENT PAPER, Wayne Shafer [9, p. 472] presented an example of a non-symmetric cardinal value allocation ${ }^{2}$ in which one agent is assigned a weight of zero and treated as a "dummy." He then left as an open problem the question of whether there can exist cardinal value allocations which assign different utilities to identical agents when all players are given strictly positive weights. This problem has also been alluded to in a somewhat different context by Champsaur $[4$, p. 389]. The purpose of this paper is to present an example which provides an affirmative answer to the question. We shall use the model and notation of Shafer's paper to which the reader is referred for further explanation.

\section{SHAFER'S MODEL AND EXAMPLE}

$A$ game with side payments $\Gamma=(A, V)$ consists of a finite set of agents $A$ and a superadditive real valued function $V$ defined on the power set of $A$, and such that $V(\phi)=0$. Each $S \subset A$ is a coalition and $V(S)$ is the "payoff" which that coalition can guarantee its members. The Shapley Value (see [10]) of a game $\Gamma$ attempts to define a "fair division" of payoffs by assigning to each player the expected value of the incremental gain he brings to all possible coalitions, assuming they are all equally likely to form. Imputations are assigned to players according to the rule

$$
s_{a}=\sum_{S \subset A} \frac{(|S|-1) !(|A|-|S|) !}{|A| !}[V(S)-V(S \backslash\{a\})] .
$$

A finite exchange economy is a sequence of ordered triples $E=\left\{\left(X_{a}, u_{a}, \omega_{a}\right)\right\}_{a \in A}$ where $A$ is a finite set of agents, and $\left(X_{a}, u_{a}, \omega_{a}\right)$ are the characteristics of the agent. Here, $X_{a} \subset R_{+}^{l}$ is the consumption set of agent $a ; \omega_{a} \in R_{+}^{l}$ is his initial endowment and $u_{a}: X_{a} \rightarrow R$ is his utility function (assumed unique up to a linear affine transformation). An allocation for $E$ is $\left\{x_{a}\right\}_{a \in A}$ such that $x_{a} \in X_{a}$ for each $a$ and $\sum_{a \in A}\left(x_{a}-\omega_{a}\right)=0$. To each finite exchange economy $E$ and each vector of "weights" $\lambda \in R_{++}^{|A|}$ we may associate a game $\Gamma=\left(A, V_{\lambda u}\right)$ according to the rule

$$
V_{\lambda u}(S)=\max \left\{\sum_{a \in S} \lambda_{a} u_{a}\left(x_{a}\right) \mid \sum_{a \in S}\left(x_{a}-\omega_{a}\right)=0\right\} .
$$

\footnotetext{
${ }^{1}$ We would like to thank William Thomson and an anonymous referee for several helpful comments.

${ }^{2}$ See Aumann [1] for a distinction between ordinal and cardinal value allocations.
} 
An allocation $\left\{x_{a}\right\}_{a \in A}$ is a cardinal value allocation for $E$ if for some set of weights $\lambda_{a} u_{a}\left(x_{a}\right)$ is the Shapley value of each player in the associated side payment game. Two agents are identical if they have the same characteristics; and a cardinal value allocation is symmetric if identical agents are assigned the same utility.

Shafer's example (2) both illustrates the concept of cardinal value allocation and points out a "peculiarity" of value. There are three agents $\{0,1,2\}=A$ and two commodities $x$ and $y$. Utility functions and endowments are

$$
\begin{aligned}
& u_{0}\left(x_{0}, y_{0}\right)=\left[\frac{1}{2} x_{0}^{\beta}+\frac{1}{2} y_{0}^{\beta}\right]^{1 / \beta}, \quad \omega_{0}=(0,0), \\
& u_{i}\left(x_{i}, y_{i}\right)=\left[\frac{1}{2} x_{i}^{\rho}+\frac{1}{2} y_{i}^{\rho}\right]^{1 / \rho}, \quad i=1,2, \\
& \omega_{1}=(1,0), \quad \omega_{2}=(0,1)
\end{aligned}
$$

for $0 \leqslant \rho<\beta \leqslant 1$. For weights $\lambda_{0}=\lambda_{1}=\lambda_{2}=1$, one may easily compute characteristic functions for possible coalitions upon noting that for all $x, y\left[\frac{1}{2} x^{\beta}+\frac{1}{2} y^{\beta}\right]^{1 / \beta} \geqslant$ $\left[\frac{1}{2} x^{\rho}+\frac{1}{2} y^{\rho}\right]^{1 / \rho}$ with equality only if $x=y$. The Shapley values are

$$
s_{0}=\frac{1}{3}\left[\left(\frac{1}{2}\right)^{1 / \beta}-\left(\frac{1}{2}\right)^{1 / \rho}\right], \quad s_{1}=s_{2}=\frac{1-s_{0}}{2},
$$

and the value allocation is $\left(x_{i}, y_{i}\right)=\left(s_{i}, s_{i}\right)$ for $i=0,1,2$. The value allocation thus assigns positive consumption to an agent with no endowment and is therefore not in the core, since clearly the coalition $\{1,2\}$ can block the above value allocation.

A further example constructed from this by Shafer shows that by adding a "dummy" player we can obtain a non-symmetric cardinal value allocation. Add an additional person (agent 3 ) with characteristics identical to agent 0 and assign weights $\lambda_{3}=0$ and $\lambda_{0}=\lambda_{1}=\lambda_{2}=1$. The Shapley values of agents $0,1,2$ remain unchanged but that of agent 3 is $s_{3}=0$. Hence, the value allocation is $\left(x_{i}, y_{i}\right)=$ $\left(s_{i}, s_{i}\right)$ for $i=0,1,2,3$ and agents 0 and 3 are not treated symmetrically. However, in Shafer's words, "this still leaves open the more interesting possibility of a non-symmetric value allocation in which each agent receives a positive weight."

\section{A NON-SYMMETRIC CARDINAL VALUE ALLOCATION WITH POSITIVE PLAYER WEIGHTS}

Upon further reflection, it will become clear that Shafer almost provided the answer to his own question. The critical feature of his examples is that agent 0 always has a higher elasticity of substitution than agents 1 and 2 and that all utility functions are normalized on $u_{i}(1,1)=1$. Thus, whenever weights assigned to the three agents are equal, the maximum value which defines a coalition's characteristic function is achieved by allowing agent 3 to consume all goods in any coalition of which he is a member and for which the endowments of $x$ and $y$ are not equal. The condition that $\left[\frac{1}{2} x^{\beta}+\frac{1}{2} y^{\beta}\right]^{1 / \beta}>\left[\frac{1}{2} x^{\rho}+\frac{1}{2} y^{\rho}\right]^{1 / \rho}$ implies agent 0 has a superior "utility producing technology." This is not true, however, for any choice of weights. Clearly, the choice of zero weight removes any advantage but 
it is not the only one which does. Given any choice of $\lambda<\left(\frac{1}{2}\right)^{((1 / \rho)-(1 / \beta))}$, we find that $\lambda\left[\frac{1}{2} x^{\beta}+\frac{1}{2} y^{\beta}\right]^{1 / \beta}<\left[\frac{1}{2} x^{\rho}+\frac{1}{2} y^{\rho}\right]^{1 / \rho}$ for any values except $x=y=0$.

We may now construct an example of a non-symmetric cardinal value allocation with positive player weights by making use of the above observation. To Shafer's example (2), add another agent (3) identical to agent zero and assign weights $\lambda_{0}=\lambda_{1}=\lambda_{2}=1$ and $0<\lambda_{3}<\left(\frac{1}{2}\right)^{((1 / \rho)-(1 / \beta))}$. The agents' Shapley values are then

$$
s_{0}=\frac{1}{3}\left[\left(\frac{1}{2}\right)^{1 / \beta}-\left(\frac{1}{2}\right)^{1 / \rho}\right], \quad s_{1}=s_{2}=\frac{1-s_{0}}{2}, \quad s_{3}=0,
$$

and the value allocation is $\left(x_{i}, y_{i}\right)=\left(s_{i}, s_{i}\right), i=0,1,2,3$, which clearly treats agents 0 and 3 in a non-symmetric manner.

\section{CONCLUSIONS}

The above example casts doubt on any interpretation of the weights as a meaningful "endogenous utility comparison" as has been suggested in Shapley [11]. This certainly reinforces the negative results given by $\left[7,8,9,12\right.$, and 13]. ${ }^{3}$

Recently, Aumann [3] has axiomatized the nontransferable utility value (NTU). It is important to note that the axioms refer to values as payoff vectors only and the positive weights associated with the value do not appear explicitly in the axioms. However, no symmetry axiom is posed by Aumann. In fact, our counterintuitive example shows that if the weights are to be endogenously determined, no symmetry axiom can be imposed.

We may conclude that there exist value allocations which treat identical agents quite differently. For purposes of comparison it should be noted that all competitive equilibrium allocations possess the equal treatment property as do other game solution concepts such as the Shapley value when applied to games with transferable utility and the Nash solution. Finally, we have not examined the question of whether the unequal treatment of cardinal value allocations disappears as the economy becomes large. Champsaur [4], Mas-Colell [6], and Cheng [5] have shown that the set of cardinal value allocations converges to the set of competitive equilibrium allocations as the number of agents goes to infinity if a symmetry requirement is satisfied. It remains an open question whether the value convergence theorem remains valid for allocations without the equal treatment property.

Wayne State University,
and
University of Minnesota and Wayne State University

Manuscript received September, 1983; revision received April, 1984.

${ }^{3}$ See Aumann [2] for a critical discussion of the counter-intuitive examples of Roth [7] and Schafer [9]. 


\section{REFERENCES}

[1] Aumann, R. J.: "Values of Markets with a Continuum of Traders," Econometrica, 43(1975), 611-646.

[2] - :On the Non-Transferable Utility Value," IMSSS-Economics, Stanford University TR-380, 1982.

[3] —_: "An Axiomatization of the Non-Transferable Utility Value," IMSSS-Economics, Stanford University, TR-415, 1983.

[4] Champsaur, P.: "Cooperation vs. Competition," Journal of Economic Theory, 11(1975), 394 417.

[5] Cheng, H.: “On Dual Regularity and Value Convergence Theorems," Journal of Mathematical Economics, 8(1981), 37-57.

[6] Mas-Colell, A.: "Competitive and Value Allocations of Large Exchange Economies," Journal of Economic Theory, 14(1977), 419-438.

[7] ROTH, A.: "Values for Games Without Side Payments: Some Difficulties with Current Concepts," Econometrica, 48(1980), 457-465.

[8] SCAFUri, A., AND N. YANnelis: "Some Observations on Value in Public Goods Economies," Mimeo, University of Minnesota, 1984.

[9] ShAFER, W. J.: "On the Existence and Interpretation of Value Allocation," Econometrica, 48(1980), 467-474.

[10] Shapley, L. A.: "A Value for an n-Person Game," in Contributions to the Theory of Games II, ed. by H. W. Kuhn and A. W. Tucker. Princeton, New Jersey: Princeton University Press, 1953.

[11 ] : "Utility Comparison and the Theory of Games," in La Decision, ed. by Guilbaud. Paris, France: Editions du CNRS, 1969.

[12] ThOMSON, W.: "On the Manipulability of Shapley Value," International Journal of Game Theory, (forthcoming).

[13] YANNELIS, N. C.: "Existence and Fairness of Value Allocation Without Convex Preferences," Journal of Economic Theory, 31(1983), 283-292. 